\title{
Stefan Zweig e o exílio do mundo
}

Cláudia Carneiro Peixoto ${ }^{1}$

Antônio Carlos Mousquer ${ }^{2}$

\begin{abstract}
The article analyzes the meaning of "being in the world" and "being of the world", based on the dialogue with Stefan Zweig's autobiographical, fictional and historiographical narratives (1881-1942), and Hannah Arendt's political philosophy (1906-1975), jews who lived the experience of being stateless and living in exile because of nazi persecution.

Keywords: Stefan Zweig; Hannah Arendt; To be in the world; To be of the world.
\end{abstract}

Resumo: O artigo analisa o sentido de "ser no mundo" e "ser do mundo", a partir do diálogo com as narrativas autobiográfica, ficcional e historiográfica de Stefan Zweig (1881-1942), e a filosofia política de Hannah Arendt (1906-1975), judeus que viveram a experiência de serem apátridas e viverem no exílio, em virtude das perseguições nazistas.

Palavras-chaves: Stefan Zweig; Hannah Arendt; Ser no mundo; Ser do mundo.

\section{Exílio no país do futuro}

Stefan Zweig nasceu na Áustria, de ascendência judaica. Atuou em diversas atividades como escritor, tradutor, dramaturgo, jornalista, biógrafo e colecionador. Embora desfrutasse de grande fama como escritor, com a ascensão do nazismo, tornou-se à revelia de sua vontade estrangeiro, exilado e hóspede em toda parte, como inscreve em sua autobiografia:

Assim, não pertenço a lugar algum, em toda parte sou estrangeiro ou, na melhor das hipóteses, hóspede; a própria pátria que meu coração elegeu para si, a Europa, perdeu-se para mim, desde que se autodilacera pela segunda numa guerra fratricida. Contra a minha vontade eu me tornei testemunha da mais terrível derrota da razão e do mais selvagem triunfo da brutalidade dentro da crônica dos tempos; nunca - eu não registro isso de maneira alguma com orgulho, mas sim com vergonha - uma geração sofreu tamanho retrocesso moral, vindo de uma tal altura intelectual como a nossa. (ZWEIG, 2014, p. 14)

Zweig viajou por diversos países como escritor mundialmente conhecido e, a partir de 1935, emigrou na condição de apátrida, tendo lhe sido oportunizado fixar-se nos Estados Unidos, país que acolhera muitos de seus amigos e sua ex-mulher. Em 1940,

1 Doutoranda em História da Literatura na Universidade Federal do Rio Grande (FURG) e membra dos projetos de pesquisa "Heterobiografias do trauma: um olhar literário e interdisciplinar para a experiência do trauma" e "Direito e justiça social".

2 Doutor em Lingüística e Letras pela Pontifícia Universidade Católica do Rio Grande do Sul e PhD pela Université Sorbonne Nouvelle Paris 3. Professor Associado da Universidade Federal do Rio Grande. 
é-lhe concedida a cidadania britânica, mas Zweig prefere exilar-se no Brasil. Antes de aqui aportar em definitivo, o autor fizera uma incursão anterior, em 1936, ano em que a ditadura de Vargas já torturava presos políticos em seus porões, entre os quais, muitos intelectuais e escritores. Também neste ano, Olga Benário Prestes, alemã de origem judaica, presa pelo governo Vargas, foi deportada grávida de seu companheiro brasileiro, Luís Carlos Prestes, e entregue à Gestapo, na Alemanha. Olga morreria anos depois, em um campo de concentração nazista.

A relação de Zweig com o Brasil toma dimensões fabulosas, haja vista o seu encantamento pelo país sul-americano desde a infância. A admiração, revelada em um discurso de agradecimento em razão do convite feito pelo governo brasileiro para uma série de palestras no Rio de Janeiro e em São Paulo, é relatada em seu livro Castellio contra Calvino: uma consciência contra a violência:

O Brasil sempre foi para mim um país mágico. Em criança, tinha orgulho de colecionar e colar em meu álbum os bonitos selos postais; quando rapaz lia com entusiasmo as maravilhas sobre o rio Amazonas, e já adulto, sempre ouvia coisas admiráveis sobre a beleza desta cidade, sobre a vossa cultura especial e incomparável, e sobre a originalidade de vosso país. E, no correr dos anos, sempre cresceu de maneira indomável meu desejo de empreender a longa viagem. Enfim, o desejo foi satisfeito. (ZWEIG, 1943, p. 140)

Zweig foi recebido, em 1941, com celebrações do governo Vargas à sua notoriedade internacional, e deixou-se imergir em incursões nas quais pequenos recortes do Brasil lhe eram apresentados em cerimônias oficiais e passeios com amigos. Teria a dura realidade política da ditadura do Estado Novo escapado à argúcia do escritor? Zweig não desconhecia a natureza ditatorial do governo brasileiro e, mesmo assim, credita-lhe um espírito de conciliação e a concessão de liberdades individuais maiores que a "maioria dos países europeus" (ZWEIG, 2013a, p. 23). O expatriamento e o exílio impostos pelo regime totalitário nazista perpassam a narrativa autobiográfica e, certamente, assumem um peso significativo na avaliação positiva que o autor faz do regime político instalado no Brasil, que o acolhera de modo amistoso (ZWEIG, 2013, P. 13-14). No entanto, não podemos fugir à constatação de que a neutralidade política do autor e o seu completo alheamento diante da realidade brasileira foram instrumentalizados e aproveitados pelo governo Vargas (DINES, 2012, p. 47).

Da primeira visita ao Brasil, Zweig mantém o deslumbramento, registrado em sua obra laudatória Brasil: um país do futuro (1941), uma leitura ingênua dos trópicos, em que as mazelas do colonialismo cedem lugar à percepção de uma feliz convivência entre os diferentes grupos étnicos, na crença de uma miscigenação bem-sucedida, sem adentrar o campo de uma análise crítica das injustiças sociais materializadas na miséria e na discriminação racial:

Para surpresa, descobre-se que todas essas raças, que já pela cor evidentemente se distinguem uma das outras, convivem em plena harmonia e, apesar das diferentes origens, apenas competem pelo empenho de acabar com suas diversidades a fim de se tornarem rapidamente brasileiros, de constituir uma nação nova e homogênea. (ZWEIG, 2013a, p. 18)

É preciso ainda ter em vista que a narrativa historiográfica do autor ao mesmo tempo que apresenta uma visão acrítica, em que sobressaem aspectos que tornam o Brasil 
promissor e convidativo, também serve para angariar a simpatia do Governo Vargas e abrir caminho para a obtenção de uma futura permanência no país. Além disso, ao compor o seu longo e detalhado panegírico, Zweig cria um lugar imaginário, uma ucronia em que se despluga do tempo presente, o que apreendemos em expressões cunhadas pelo autor, conhecidas até os dias de hoje, como "Brasil, país do futuro" e "ponte para o futuro"3:

Pacifista, autodeclarado apolítico e neutro, Zweig manteve-se a maior parte de sua vida distante de qualquer ligação ou participação explícita com questões políticas. Somente nos últimos anos de sua vida, dedicou-se a denunciar as atrocidades do nazismo como uma calamidade pessoal que o vitimara enquanto judeu e a causa do sentimento de desterro:

Não me adiantou ter educado o coração em quase meio século para que pulsasse como o de um cidadão do mundo, "citoyen du monde". Não: no dia em que perdi meu passaporte descobri, aos cinquenta e oito anos, que com a pátria perde-se muito mais do que um pedaço de terra e asfronteiras. (ZWEIG, 1999, p. 491)

Somente em seus últimos textos, o autor denuncia o nazismo como uma violência ao povo judeu, o que podemos inferir do texto Aos que não podem falar, lido na rádio em 1940, e de sua última obra de ficção, Xadrez, uma novela, finalizada pouco tempo antes de sua morte.

\section{Ser no mundo e ser do mundo}

Na obra A condição humana, publicada em 1958, Hannah Arendt designa por meio da expressão vita activa, as três atividades humanas básicas, a saber, o trabalho, a obra e a ação. O trabalho, de acordo com a autora, diz respeito ao processo biológico e sua condição humana é a própria vida. A obra implica no artifício humano que acrescenta ao mundo coisas artificiais e a sua condição humana é a mundanidade. A ação, por sua vez, é a única atividade que ocorre diretamente entre os homens, e não a partir ou com o Homem. Ela é intangível, não deixa vestígios e sua condição humana é a pluralidade que, para a autora, não se resume a ser a conditio sine qua non, mas é também a conditio per quam da vida política. Em outras palavras, a pluralidade, o fato de que os homens vivem na Terra e habitam o mundo, não é apenas a condição da política, mas a condição por intermédio da qual a política vem a existir (ARENDT, 2010, p. 8-10).

O espaço público propicia que o debate dos assuntos que dizem respeito a todos os membros do corpo político ocorra. No espaço público, por meio da fala - lexis - e da ação - práxis - em igualdade vivida na diferença, em concerto umas com as outras, as pessoas têm a oportunidade de participar dos assuntos e das decisões que a todos dizem respeito (ARENDT, 2010, p. 79). Neste contexto, compreendemos por qual razão a política somente pode ocorrer em um espaço criado entre os homens que é a esfera pública. Para Arendt, a política trata do mundo que, por sua vez, diz respeito à pluralidade humana, levando em consideração que a perpetuação ou a manutenção do mundo só tem sentido se o mundo for habitado pelos seres humanos (ARENDT, 2009, p. 238).

3 A expressão "Uma ponte para o futuro" ocupou lugar de destaque, em 2015, na agenda política publicada pelo Partido do Movimento Democrático Brasileiro (PMDB), que apregoava os princípios neoliberais que regeriam o futuro governo de Michel Temer, em 2016, na presidência da República (CAVALCANTI; VENERIO, 2017, p. 140). 
Arendt busca na estética kantiana a percepção de sociabilidade, a partir da questão colocada pelo filósofo, na Crítica da Faculdade do Juízo: por que é necessário que existam os homens? A resposta "porque nenhum homem pode viver sozinho" nos encaminha para o sentido da interdependência humana que ocorre não somente em virtude das contingências e preocupações, mas também em virtude da faculdade humana de pensar, pois a mente humana não funciona à margem da sociedade (ARENDT, 2003, p. 28).

Com o antagonismo platônico entre a vita contemplativa e a vita ativa, e a desvalorização da persuasão (ARENDT, 2009, p. 47), passa-se à valorização da "contemplação", do alheamento político ou da apolitia e da experiência do eterno, em detrimento da vita ativa e do bios politikos, instância implicada no pertencimento a um mundo comum em que o ser e o aparecer coincidem (Arendt, 2010, p. 25). Arendt ressalta que a decadência da política grega teria feito surgir o problema do apolitismo, ou seja, a condição em que o homem, embora tenha que viver em sociedade, escolhe viver alheio à participação no espaço público, numa condição de negação do político, enquanto espaço da pluralidade. Em outras palavras, ao enfatizar a apolitia, Arendt nos indica a perda do espaço que une e separa as pessoas e instaura o mundo comum "entre" elas (ARENDT, 2009, p. 46). Sem o mundo comum, instala-se o deserto, como testemunham com os regimes totalitários nazista e stalinista (ARENDT, 2008, p. 18). Arendt busca no sentido romano de estar entre os homens a ideia daquilo que se "situa entre as pessoas e que, portanto, é capaz de relacioná-las e mantê-las juntas” (2010, p. 228). Nesse sentido, ao deixar de pertencer a um mundo comum, engendra-se a desolação de ser no mundo, ou seja, de apenas habitá-lo, sem constituir nenhum vínculo de pertencimento que o ser do mundo constitui. Para Arendt, é o estar entre os homens, na pluralidade e singularidade, mostrando-se e aparecendo aos seus semelhantes, assumindo a responsabilidade e o cuidado pela permanência do mundo, não apenas no presente, mas pelo futuro, que diz respeito às gerações vindouras, que significa ser do mundo.

O breve esboço da filosofia política de Hannah Arendt contribui para que possamos melhor compreender a crítica que, em 1943, a autora fez na resenha intitulada Stefan Zweig: os judeus no mundo de ontem, sobre a obra Autobiografia: o mundo de ontem, escrita por Stefan Zweig, em 1942. Arendt denuncia a apolitia e o individualismo do autor, ressaltando a sua excessiva preocupação com a dignidade pessoal, o seu sentimento de abandono diante da perda da fama, o lamento da exclusão da sociedade de artistas e literatos a que se sentia ligado e a sua hipersensibilidade à humilhação social. Os desastres que assolaram os judeus, no século XX, analisa Arendt, foram oriundos também da alienação da realidade política e dos perigos nela inerentes (2016, p. 557).

Alguns rastros ${ }^{4}$ autobiográficos e o último escrito ficcional de Stefan Zweig delineiam os elementos apontados por Arendt em sua resenha, e nos auxiliam na distinção entre ser no mundo e ser do mundo. Apreendemos, por exemplo, em sua autobiografia o sentimento de estrangeiridade, de não pertencimento e um esforço em demarcar a sua apolitia, elementos com os quais o autor justificava a sua negação em participar de instâncias políticas que não fossem de pacifismo e de neutralidade:

4 Poderíamos acrescentar outros rastros da rejeição de Zweig à política presente no ensaio historiográfico sobre o Brasil: "A política, com todas as suas perfídias, ainda não é o eixo da vida privada nem o centro de todo o pensar e sentir. Logo que se chega ao país, a primeira surpresa, que se renova diariamente de maneira feliz, é descobrir a maneira gentil e pouco fanática com que as pessoas convivem naquele espaço imenso" (ZWEIG, 2013a, p. 20). 
não pertenço a lugar algum, em toda parte sou estrangeiro ou, na melhor das hipóteses, hóspede; a própria pátria que meu coração elegeu para si, a Europa, perdeu-se para mim, desde que se autodilacera pela segunda vez numa guerra fratricida. (ZWEIG, 2014, p. 14)

Diante dos horrores do totalitarismo alemão, obrigado ao exílio, Zweig refugia-se também interiormente, buscando no século XIX o enlevo e encantamento da "Época de Ouro da Segurança", em que não existiam as perseguições nazistas e o amontoamento humano em campos de concentração. No século XIX, o autor encontrou o brilho e a fama dos literatos, em que fulguravam os nomes dos autores nos livros estampados nas vitrines das livrarias, e o judeu genial era aceito pelos Estados europeus por meio de títulos de cidadania provisória e incluído nos mais atraentes círculos da boa sociedade. Zweig foge, assim, do presente em que a posição dos judeus na Europa havia se tornado ambígua e insegura, e a proteção cingida pela fama do gênio mostrara-se insuficiente diante do nazismo (ARENDT, 2016, p. 563) e refugia-se, exila-se no tempo imaginário do século XIX, no país do futuro.

Perder a fama, o sucesso e a permanência na "sociedade internacional do sucesso", significou ser rebaixado à vala dos homens comuns, o que obrigou o autor a viver somente como o "Judeu Zweig" (ARENDT, 2016, p. 564-565). Sua autobiografia revela o saudosismo pelo tempo de outrora, o "mundo de ontem" expressão usada em uma oposição aos desastres do presente, à idealização do passado e uma latente compreensão de impossibilidade de futuro. O uso recorrente do termo "ontem" vai além da ideia de um passado glorioso, pois reivindica um tempo imaginário, o descolamento da realidade, entendimento contrário ao tratamento do termo "ontem" com o significado de "transições, passagem, virada de página, avanço e retrocesso" (DINES, 2014, p. I).

A ucronia de Zweig também pode ser pensada à luz de suas constantes viagens e perambulações pelo mundo, bem como em sua decisão de se estabelecer no Brasil, como um refúgio à altura de sua concepção de paraíso perdido, em que o tempo imaginário se une ao lugar imaginário para viver o seu exílio. O presente da guerra, dos bombardeios, das perseguições incessantes aos judeus simbolizava um "mundo insone", expressão usada no título e ao longo de um de seus textos, publicado três semanas após a deflagração da Primeira Guerra Mundial (DINES, 2013, p. 197). Mais que o lamento profundo pela eclosão da Primeira Guerra Mundial, o mundo insone exprime a perda de uma época em que a segurança, o sossego, o descanso e a paz eram ainda possíveis. De modo trágico, o autor que se mataria com morfina, afirma: "só o insone conhece a doçura do sono reconquistado" (ZWEIG, 2013, p. 203).

Desconfiado da política, Zweig experimentou os acontecimentos de sua época como uma espécie de tragédia íntima, um abalo à sua dignidade pessoal (ARENDT, 2016, p. $552)$, o que se refletiu na vergonha que sentiu quando se viu obrigado a viver como um apátrida (ZWEIG, 2013, p. 187). Em suas palavras, "antigamente, o homem tinha só corpo e homem. Hoje também precisa de um passaporte, ou nem é tratado como homem" (Zweig, 1999, p. 488).

O desgosto para a sua hipersensibilidade e a humilhação social se colocavam acima de quaisquer convicções políticas, ou seja, a desonra e a desgraça eram vivenciadas em um plano exclusivamente pessoal e não como uma experiência também comum ao povo judeu que vivia as mesmas condições de exílio e expatriamento do autor. Zweig vivencia as imposições do Estado nazista como um literato, inconsolável diante da perda da fama, em que a maior "desgraça é o anonimato" (ARENDT, 2016, p. 552-553). 
Zeloso de sua autonomia pessoal, usada como justificativa para a sua neutralidade e apolitia, o autor admirava os objetores de consciência, enquanto sujeitos que afrontavam as normas consideradas injustas por razões pessoais e assumiam a responsabilidade por seus atos de desobediência, afirmando-se incapaz, contudo, de romper a sua neutralidade, em virtude de seu caráter indeciso, "sem nenhuma propensão ao heroísmo" (ZWEIG, 2014, p. 208). Zweig jamais assumiu ser um objetor de consciência, tendo se contentado com uma forma de liberdade que afirmava ser peculiar ao expatriado enquanto sujeito liberado de qualquer tipo de vínculo: “o expatriado se torna livre num sentido novo, e só quem já não está ligado a nada não precisa mais ter consideração com nada” (ZWEIG, 1999, p. 7-8).

$\mathrm{Na}$ ficção zweiguiana, o heroísmo, a ideia do vencedor, cedem lugar ao vencido, ao derrotado, como podemos discernir em personagens escamoteadas pela sorte como Tersites, o anti-herói morto por Aquiles; o profeta bíblico Jeremias e a profetisa troiana Cassandra; Joseph Fouché, este último uma figura ambígua da revolução francesa, dentre outros. A preferência pelos vencidos se faz acompanhar pela narrativa acerca da existência de uma superioridade psicológica presente nestas figuras:

Sempre me seduziu mostrar o endurecimento interior que toda forma de poder gera nas pessoas, o enrijecimento anímico que a vitória produz em povos inteiros, para contrapor a isso o poder da derrota que revolve dolorosamente a alma. Em meio à guerra, enquanto os outros ainda procuravam demonstrar uns aos outros a vitória infalível, triunfando antes da hora, eu já me lançava no mais profundo precipício da catástrofe e buscava a subida. (ZWEIG, 2014, p. 228)

A derrota será retomada no último texto de ficção escrito por Zweig, entre os anos 1938 e 1941, finalizado no Brasil e intitulado Schachnovelle, Xadrez, uma novela, publicado postumamente. Mais que simbolizar a derrota pessoal, a última novela de Zweig metaforiza a derrota do povo judeu diante das calamidades impostas durante a Segunda Guerra Mundial. O jogo de xadrez toma o centro temático de uma história que mescla memória e suposições para relatar um intrincado embate, a tradução mais fiel da criatividade artística, sua gênese e suas variações:

Criar é uma luta constante entre inconsciência e consciência. Sem esses dois elementos não é possível realizar-se o ato artístico. Ambos esses elementos básicos são indispensáveis; o artista é um escravo dessa lei de contraste da compensação criadora entre consciente e inconsciente. Dentro dessa lei, ele se acha livre. A melhor comparação para esse cativeiro e, ao mesmo tempo, liberdade artística é, talvez, a de um jogo de xadrez. No xadrez, dois grupos, preto e branco, defrontam-se para uma partida. Ali o jogo está limitado aos 64 campos, ao passo que a produção artística se restringe as quarenta ou cinquenta mil palavras da língua, ao prisma das cores ou à escala dos sons. Mas, da mesma forma como nos 64 campos se produzem variações inúmeras entre o preto e o branco, pois um jogo nunca é igual ao outro, o processo de produção artística também será completamente diferente em cada artista. (ZWEIG, 1937, p. 230)

A narrativa, feita em primeira pessoa, nos apresenta o cotidiano em um navio que sai de Nova Iorque com destino a Buenos Aires. As personagens que protagonizam a novela são o campeão mundial de xadrez, Mirko Czentovic - descrito como uma figura grotesca, quase cômica e aparvalhada, gênio do xadrez que, contrário ao que pode poderia esperar, é uma criatura rude e sem nenhum requinte intelectual -, e um advogado judeu-vienense, Dr. B. Enfastiado com a viagem, o narrador, ao saber da presença do campeão mundial 
de xadrez, no navio, planeja chamar a sua atenção jogando com sua esposa uma partida de xadrez. Em um primeiro momento, consegue despertar a atenção de um milionário escocês, McConnor, que ao conhecer o objetivo do narrador, consegue combinar uma partida paga com o campeão mundial. Após perder a primeira partida, McConnor pede uma revanche, durante a qual, a inusitada intervenção de um homem no jogo, contribuindo com dicas, resulta na vitória do milionário escocês. O jogador que intervém no auxílio ao escocês é o advogado Dr. B. Vencida a revanche, o narrador planeja outra partida, dessa vez entre o campeão mundial e o advogado Dr. B. Este último, ao receber o convite do narrador, conta-lhe a sua estória. Assim ficamos sabendo que após a invasão da Áustria pelos alemães, Dr. B. foi confinado pela Gestapo e mantido em completo isolamento, em um quarto de hotel, saindo esporadicamente apenas para ser interrogado. Depois de quatro meses de isolamento, na ocasião em que aguardava ser interrogado, o advogado consegue furtar um manual de xadrez e decora todas as partidas presentes no livro. Inicialmente, o manual alivia o sofrimento do advogado no isolamento, no entanto, depois de decorar as partidas, nova agonia toma conta do advogado que, no auge do desespero tenta, sem sucesso, jogar sozinho, simulando, num exercício de abstração, em um tabuleiro imaginário, as jogadas contra si mesmo. A impossibilidade de jogar contra si mesmo leva o advogado a um colapso mental que resulta no seu encaminhamento para o hospital, ocasião em que consegue, por meio da ajuda de um médico, ver-se livre do aprisionamento pela Gestapo. Depois de liberado, o advogado embarca em um navio para os Estados Unidos e, deste país, viaja em outra embarcação para a Argentina. Dr. B vence a primeira partida com o campeão mundial que solicita uma revanche e, no desenrolar desta, o advogado não consegue evitar a memória angustiante dos dias de isolamento. Tomado pela mesma dissociação e confusão mental que experimentara no isolamento, Dr. B. alheia-se à partida real com o Czentovic e passa a simular jogadas imaginárias. Ao se dar conta e, em estado de estupor, o advogado desiste da partida, e abandona a partida (ZWEIG, 2015).

A descrição de um vazio absoluto, no período do confinamento no quarto do hotel, se traduz também no apagamento da realidade, isto é, de "seres que aparecem no mundo". A leitura arendtiana implicada na ideia de mundo comum exige a presença de espectadores e no reconhecimento mútuo (ARENDT, 2010b, p. 63). Nesse sentido, ao deixar de pertencer a um mundo comum, engendra-se para o Dr. B. a desolação, é destituído do pertencimento que vai além de meramente ser no mundo, ou seja, de apenas habitá-lo. Para Arendt, é o estar entre os homens, na pluralidade e singularidade, mostrando-se e aparecendo aos seus semelhantes, assumindo a responsabilidade e o cuidado pela permanência do mundo, não apenas no presente, mas pelo futuro, que diz respeito às gerações vindouras, que significa ser do mundo e o que assegura a própria existência da realidade: "Por um lado, a realidade do que percebo é garantida por seu contexto mundano, que inclui outros seres que percebem como eu; por outro lado, ela é percebida pelo trabalho conjunto de meus cinco sentidos" (ARENDT, 2010, p. 67).

$\mathrm{O}$ estudo do manual de xadrez, embora reequilibre provisoriamente a sanidade mental, do prisioneiro, não o assegura da mundanidade, do fato de que precisamos dos outros também para pensar e confirmar o nosso entendimento. E, ao esgotar o aprendizado das jogadas, o prisioneiro fragmenta o último vestígio de sua alteridade, esforçando-se para jogar contra si mesmo.

O vazio do isolamento, que produz o nada absoluto apontado por Zweig, gera o desamparo, o abandono total, pois "nem os pensamentos suportam o nada" (ZWEIG, 2015, p. 249), e o sujeito se vê destituído até mesmo da alteridade primeira que é o diálogo 
interior do eu consigo mesmo, numa espécie de desertificação interior. O esforço de re-estabelecer esse diálogo transparece nas tentativas de atuar como dois ao invés de ser um jogador. Para ser "dois" é necessária uma ruptura representada na abstração de um duelo consigo mesmo impossível à psique humana, uma vez que não se trata de uma alteridade do "eu comigo mesmo", mas de uma fratura, uma relação do "eu contra si mesmo".

Embora o advogado judeu não seja enviado a um campo de concentração, mas para outra forma de tortura que é a do isolamento "mais sofisticado possível" (ZWEIG, 2015, p. 249), a narrativa nos remete a diversas perspectivas interpretativas, entre as quais destacamos a desumanização dos judeus, expulsos de seus lares, condenados ao exílio ou confinados em campos de concentração, e nos coloca diante de uma forma singular de destruição da realidade com a destituição do mundo comum.

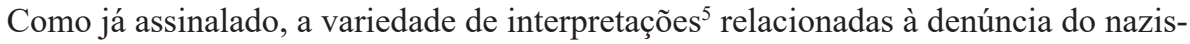
mo e de suas atrocidades, como a desumanização e destruição da psique humana, também nos possibilita estabelecer contato com a reflexão arendtiana acerca da pluralidade, do mundo comum e da interdependência humana, da necessidade do "outro" que a metáfora do jogo de xadrez anuncia por intermédio do agonismo, isto é, da competição entre adversários, e não do antagonismo, peculiar à relação existente entre inimigos e que enseja na destruição do outro. Por mais que exista determinado número de jogadas conhecidas, os jogadores jamais poderão prever com certeza qual será a jogada do seu oponente, uma vez que são dois seres que, em igualdade, desfrutam da liberdade que, na singularidade humana, implica na imprevisibilidade da ação.

\section{Considerações finais}

Os rastros autobiográficos e ficcionais evocados, no presente estudo, nos desvelam novos questionamentos, colocados diante da crise das democracias no ocidente e a negação da política como instância da cidadania e de participação popular. Nesse contexto, a alienação e a apolitia assumem forte protagonismo nas sociedades de massa, e a experiência do exílio interior, da perda do sentido da realidade propiciam campo aberto para a ucronia, tentação que a obra e a vida de Stefan Zweig nos convoca a refletir, sobretudo quando ser do mundo, na acepção do compartilhamento de experiências, de uma convivência, está diretamente ligada à responsabilidade pela permanência do mundo para as gerações futuras, o que transcende nossas vidas individuais, na medida em que a pluralidade, como assevera Arendt, implica no entendimento de que não um Homem, mas os homens habitam o planeta.

\section{Referências}

ARENDT, Hannah. Conferencias sobre la filosofía política de Kant. Barcelona: Paidós, 2003. Tradução de Carmen Corral. Introdução e edição de Ronald Beiner.

5 Destacamos a leitura: “Com a parábola sobre o jogo dos jogos, Zweig passa em revista tudo o que o horroriza na guerra: Hitler não é um caso isolado de insanidade, o nacional-socialismo é um projeto político de massas baseado na bestialidade, Czentovic não é uma pessoa, é uma multidão, entidade. Ainda não se conhecem robôs, Zweig consegue preconizá-los na figura desse campeão sem entranhas, homem sem humanidade" (DINES, 2012, p. 35) 
. Homens em tempos sombrios. São Paulo: Companhia de Bolso, 2008b. Tradução de Denise Bottmann. Posfácio de Celso Lafer.

. A promessa da política. Organização e introdução Jerome Kohn., 2 ed., Rio de Janeiro: DIFEL, 2009. Tradução de Pedro Jorgensen Jr.

. A Condição Humana. , 11 ed., Rio de Janeiro: Forense Universitária, 2010. Tradução de Roberto Raposo. Revisão técnica e apresentação de Adriano Correia

. A vida do espírito: o pensar, o querer, o julgar. $2^{\mathrm{a}}$ ed. Rio de Janeiro: Civilização Brasileira, 2010b. Tradução DE Cesar Augusto R. de Almeida, Antônio Abranches e Helena Franco Martins.

. Escritos Judaicos. Baueri/SP: Amarilys, 2016. Tradução de Laura Degaspare Monte Mascaro, Luciana Garcia de Oliveira e Thiago Dias da Silva.

CAVALCANTI, Bernardo Margulies; VENERIO, Carlos Magno Spricigo. "Uma ponte para o futuro?: reflexões sobre a plataforma política do governo Temer". Revista de Informação Legislativa: RIL, v. 54, n. 215, p. 139-162, jul./set. 2017. Disponível em $<$ https://www12.senado.leg.br/ril/edicoes/54/215/ril_v54_n215_p139.pdf >. Acesso e 14/08/2019.

DINES, Alberto. Morte no Paraíso: a tragédia de Stefan Zweig. $4^{\mathrm{a}}$ ed. Rio de Janeiro: Rocco, 2012.

ZWEIG, Stefan. Encontro com homens, livros e países. Tradução de Milton Araújo. Rio de Janeiro: Guanabara. 1937.

. Uma consciência contra a violência. Rio de Janeiro: Guanabara, 1943.

. O mundo que eu vi. Rio de Janeiro: Record, 1999. Tradução de Lya Luft.

. Brasil: um país do futuro. Porto Alegre: L\&PM, 2013a. Tradução de Kristina

Michahelles

. O mundo insone e outros ensaios. Organização e textos adicionais Alberto Dines. Rio de Janeiro: Zahar, 2013b. Tradução de Kristina Michahelees.

. Autobiografia: o mundo de ontem. Rio de Janeiro: Zahar, 2014. Tradução de Kris$\overline{\text { tina Michahelees. }}$

. Novelas Insólitas. Rio de Janeiro: Zahar, 2015. Tradução de Kristina Michahelees, Maria Aparecida Barbosa e Murilo Jardelino.

Recebido em: 26/08/2019; Aceito em: 25/09/2019 